\title{
Scaling-Up of High Pressure Torsion Using Ring Shape
}

\author{
Kaveh Edalati* and Zenji Horita \\ Department of Materials Science and Engineering, Faculty of Engineering, Kyushu University, Fukuoka 819-0395, Japan
}

A 100 mm-diameter ring sample of high purity Al $(99.99 \%)$ was processed by high-pressure torsion (HPT). It was confirmed that the results of hardness measurements were consistent with those obtained using disk samples and demonstrated that scaling-up the HPT process was feasible using the ring-shaped sample. Evaluating the advantage of using ring sample, the potential for the scaling-up arises from the fact that the ring diameter can be increased by the amount corresponding to the inner central area of disk sample. Furthermore, the applied load is entirely used for the introduction of intense strain and thus for the development of a homogeneous microstrcuture throughout the ring sample. [doi:10.2320/matertrans.MD200822]

(Received September 22, 2008; Accepted October 23, 2008; Published December 10, 2008)

Keywords: high-pressure torsion, severe plastic deformation, pure aluminum

\section{Introduction}

It has been demonstrated that processing by high-pressure torsion (HPT) provides important technology for materials development. The grain sizes of various metallic materials is refined to the submicrometer or nanometer ranges and consequently the HPT processing leads to the enhancement of strength and ductility. ${ }^{1-3)}$ Second phase particles may be refined significantly and occasionally they are dissolved into the matrix. ${ }^{4,5)}$ It is also used as a consolidation of powders without sintering process. ${ }^{6-10)}$ The HPT is applicable to a wide range of materials including relatively hard and low ductile materials such as intermetallics and Mg alloys. ${ }^{11-14)}$

Major limitation of the HPT process is that the sample size is small typically as $10 \mathrm{~mm}$ in diameter with thicknesses less than $1 \mathrm{~mm}$, and the microstructure develops inhomogeneously from the center to edge of the disk because the strain is generated in proportion to the distance from the center. ${ }^{15,16)}$ To overcome this limitation, it was shown that a ring sample may be useful ${ }^{17-19)}$ because it uses only the outer areas of the disk where homogeneous structures are developed throughout the periphery. ${ }^{19-21)}$ Furthermore, it is possible to increase the diameter by the area corresponding to the inner hollow area. ${ }^{19)}$ Provided that the rotation angle is the same, the increase in the ring diameter leads to introduction of more strain, or if the designated strain is required, less rotation is sufficient.

Now, in this report, we demonstrate that scaling-up of the HPT process is feasible by taking advantage of the ringshaped feature. Furthermore we show that a $100 \mathrm{~mm}$ ring with $3 \mathrm{~mm}$ width is successfully processed. Advantage of using ring sample is discussed in comparison with disk sample.

\section{Experimental}

High-purity Al (99.99\%) was received in a form of coldrolled sheets with $1 \mathrm{~mm}$ thickness and an area of $220 \mathrm{~mm} \times$ $150 \mathrm{~mm}$. The sheet was then cut to rings with dimensions

*Corresponding author, E-mail: kaveh.edalati@zaiko6.zaiko.kyushu-u. ac.jp

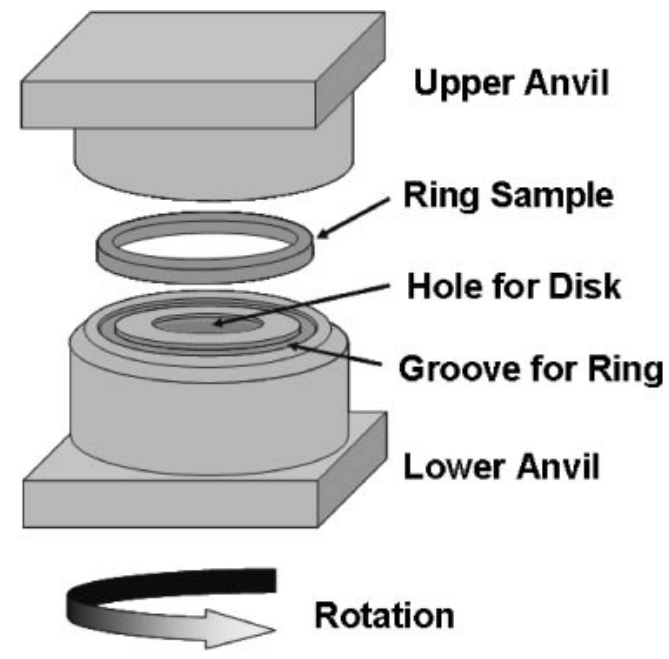

Fig. 1 Schematic illustration of ring sample and anvils for HPT.

of $94 \mathrm{~mm}$ and $100 \mathrm{~mm}$ for the inner and outer diameters, respectively, having a width of $3 \mathrm{~mm}$. Disks with $10 \mathrm{~mm}$ and $20 \mathrm{~mm}$ diameters with thicknesses of $0.8 \mathrm{~mm}$ were also prepared from cold-extruded rods for comparison. The rings and disks were subjected to annealing at $773 \mathrm{~K}$ for $1 \mathrm{~h}$ before HPT. The grain sizes after the annealing were $\sim 700 \mu \mathrm{m}$ for the disks and $\sim 100 \mu \mathrm{m}$ for the ring. According to a recent study in the same $99.99 \%$ purity $\mathrm{Al},{ }^{22}$ ) the difference in grain size has little effect on the hardness behavior with intense strain if the grain size is greater than $\sim 100 \mu \mathrm{m}$.

HPT was conducted at room temperature at a rotation speed of $1 \mathrm{rpm}$ for $1 / 4$ revolutions under a pressure of $0.3 \mathrm{GPa}$. This study used a pair of upper and lower anvils with grooves made axisymetric in $0.25 \mathrm{~mm}$ depth and $3 \mathrm{~mm}$ width. The alignment was adjusted about the center axes of the upper and lower anvils within $\pm 0.01 \mathrm{~mm}$. Schematic illustration of the upper and lower anvils with a ring sample is given in Fig. 1. For a comparison purpose, disks with $10 \mathrm{~mm}$ and $20 \mathrm{~mm}$ diameters annealed at the same conditions were placed in shallow holes made on the anvils with diameters of 10 and $20 \mathrm{~mm}$, respectively, and a depth of $0.25 \mathrm{~mm}$. Such disk samples were subjected to HPT at room temperature for 2 and $1 / 4$ revolutions, respectively under a pressure of $1 \mathrm{GPa}$ 


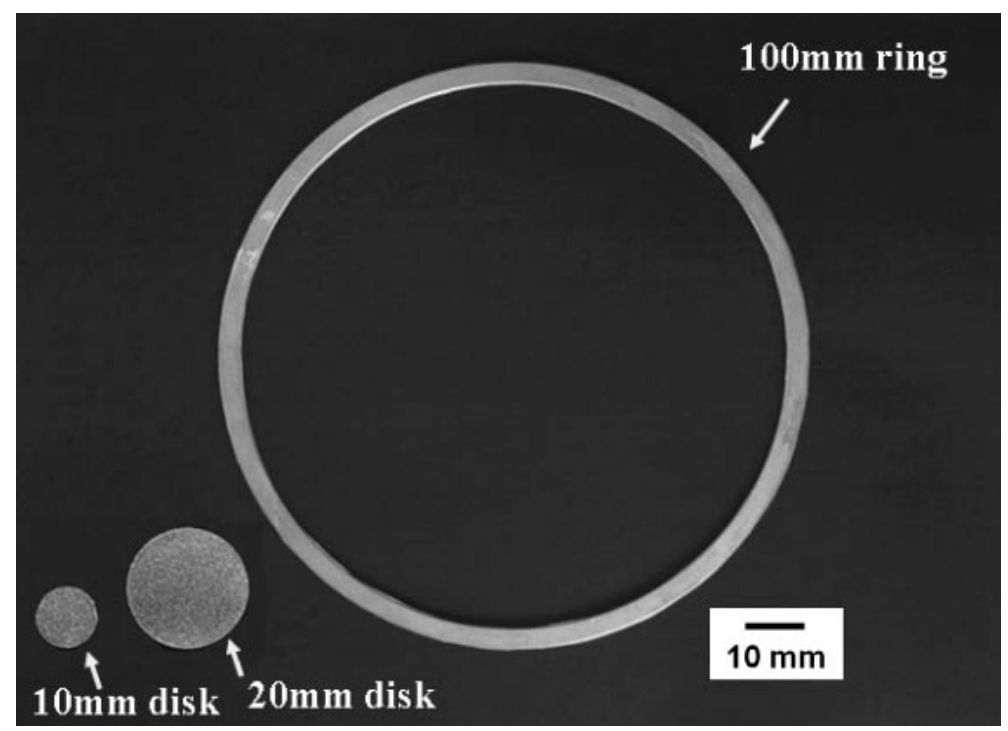

Fig. 2 Appearance of $100 \mathrm{~mm}$ ring sample and comparison with $10 \mathrm{~mm}$ and $20 \mathrm{~mm}$ disk samples.

with the rotation speed of $1 \mathrm{rpm}$. The appearance of the disks and ring samples after HPT is shown in Fig. 2.

The disks and ring samples after HPT were polished to a mirror-like surface and thus the Vickers microhardness was measured along the radii from the center to edge at 8 different radial directions for the disk samples and along the periphery for the ring samples. The average was taken from the 8 measurements at the same distance from the center of disks or rings. For each hardness measurement, a load of $50 \mathrm{~g}$ was applied for 15 seconds.

\section{Results and Discussion}

The results of hardness measurement are shown in Fig. 3 for disk and ring samples after HPT including the hardness level after annealing but before HPT. All hardness values of $10 \mathrm{~mm}$ and $20 \mathrm{~mm}$ disk samples fall on a single curve when they are plotted as a function of equivalent strain. Here, the equivalent strain was calculated by the equation given as. ${ }^{16)}$

$$
\varepsilon=\frac{2 \pi r N}{\sqrt{3} t}
$$

where $r$ is the distance from the center, $N$ is the number of revolution and $t$ is the thickness. A maximum appears at an equivalent strain of $\sim 2$ and a constant level of hardness follows at an equivalent strain of more than $\sim 7$. These features are consistent with the earlier measurements performed on high purity $\mathrm{Al}(99.99 \%){ }^{20,21)}$ The average hardness measured on the $100 \mathrm{~mm}$ ring lies well on the steady state level established by the $10 \mathrm{~mm}$ and $20 \mathrm{~mm}$ disks. It is thus confirmed that processing of the $100 \mathrm{~mm}$ ring by HPT is feasible and it is demonstrated that the use of ring samples can be a practical way for scaling up the HPT process. Although the applied pressure is less in the ring sample than in the disk samples for the present experiments, the steady state level is little affected by the applied pressure. This is also consistent with the reports that the effect of the applied pressure is insignificant on the hardness level when the imposed strain is large. ${ }^{23,24)}$

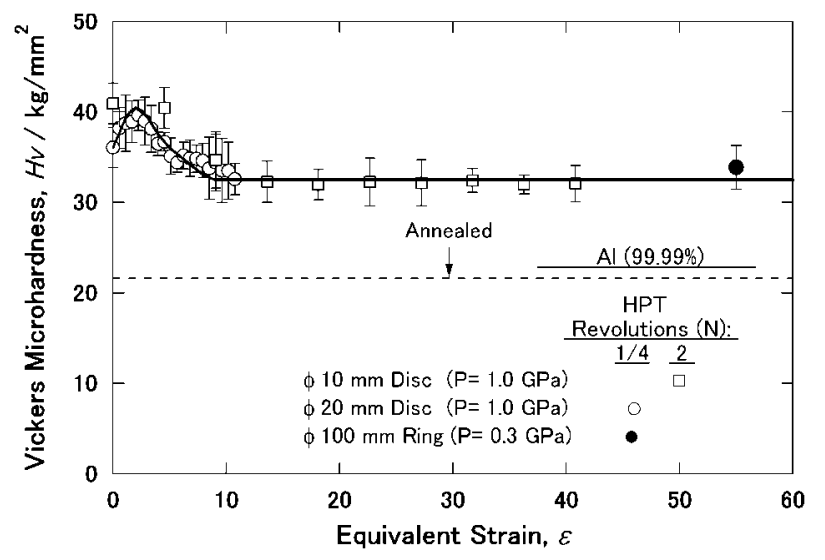

Fig. 3 Plots of Vickers microhardness against equivalent strain obtained from $10 \mathrm{~mm}$ and $20 \mathrm{~mm}$ disks including results of $100 \mathrm{~mm}$ ring sample.

A major advantage of using the ring sample for the HPT process is that it is possible to increase the diameter by the area corresponding to the inner hollow area. Furthermore, the use of ring samples eliminates microstructural inhomogeneity developed in the inner central areas of disk samples as reported earlier. ${ }^{19-21)}$ Now, we estimate quantitatively how the ring diameter can be enlarged with respect to the disk diameter, provided that the same pressure is applied on both ring and disk samples.

As illustrated in Fig. 4, the disk diameter is defined as $D_{\mathrm{D}}$ and the inner and outer diameters of ring as $D_{\mathrm{i}}$ and $D_{\mathrm{o}}$, respectively, with the ring width as $w$. Under the condition of equal area for both disk and ring $\left(S_{\mathrm{D}}=S_{\mathrm{R}}\right)$, it follows that $D_{\mathrm{o}}$ can be given as

$$
D_{\mathrm{o}}=w+D_{\mathrm{D}}^{2} / 4 w
$$

Figure 5 plots the relation of $D_{\mathrm{o}}$ against $D_{\mathrm{D}}$ for several values of $w$. This figure is read such that the $20 \mathrm{~mm}$ diameter for disk will be enlarged to $100 \mathrm{~mm}$ diameter for ring if the ring width is $1 \mathrm{~mm}$. Alternatively, it may be read such that a $100 \mathrm{~mm}$ ring with $3 \mathrm{~mm}$ width as in this study is equivalent 


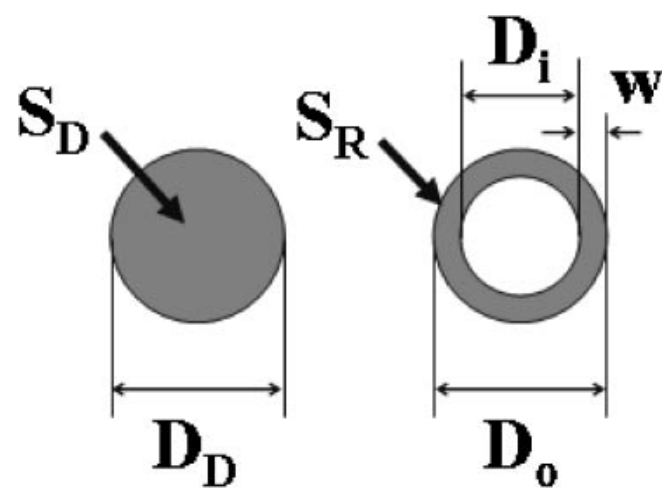

Fig. 4 Definitions of disk diameter and ring inner and outer diameters including ring width.

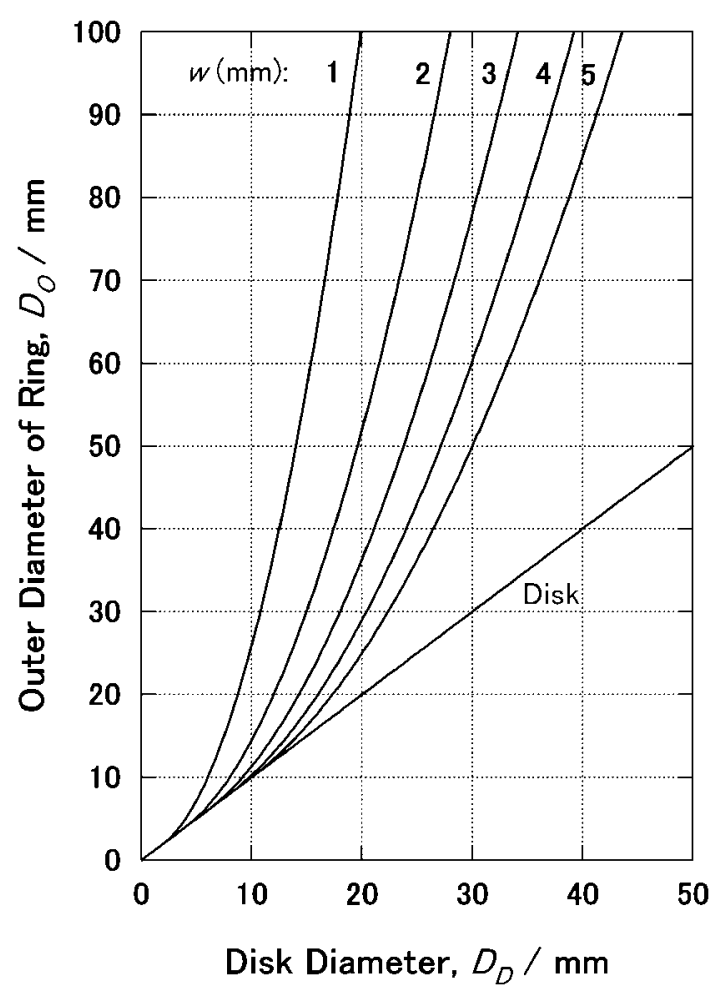

Fig. 5 Relation of ring outer diameter with disk diameter for various ring widths.

to the use of $35 \mathrm{~mm}$ disk. It should be emphasized that there is a significant difference between the use of ring samples and that of disk samples. Intense strain is equally introduced throughout the ring and a homogeneous microstructure is developed for ring samples. However, this is not the case for the disk sample because the strain introduced at the inner area is small despite the fact that the applied pressure is the same for both ring and disk samples. Another advantage of using ring sample is that the same strain is introduced by less rotation when compared with the disk sample. This is because the diameter is enlarged for the ring sample. Note that the equivalent strain is given by the product between the distance from the center $(r)$ and the rotation angle $(2 \pi N)$ as evident from eq. (1). It should be noted that, when the diameter becomes larger, the deformation occurs at faster rate even at the same rotation speed and consequently this may introduce heat generation in the sample. Although the temperature increase was negligible in this study because of only $1 / 4$ revolutions, there is in fact a report that the hardness decreased due to temperature increase at a faster rotation speed. ${ }^{25)}$

It has been said that a major limitation of the HPT process to practical application is the sample size which is small. However, the present study shows that this can be overcome using ring samples.

\section{Summary and Conclusions}

(1) It was demonstrated that scaling up of HPT is feasible using ring sample. It was shown that the $100 \mathrm{~mm}$ ring with $3 \mathrm{~mm}$ width was successfully processed by the HPT facility. The hardness results were well consistent with those obtained from the conventional disk sample.

(2) An advantage of using ring sample was discussed quantitatively. First, the ring diameter is increased by the amount corresponding to the inner hollow area. Second, the whole area of ring sample can be usable because of homogeneous introduction of strain and thus of homogeneous development of microstructure throughout the ring.

\section{Acknowledgements}

One of the authors (KE) thanks the Islamic Development Bank for a scholarship. This work was supported in part by the Light Metals Educational Foundation of Japan, in part by a Grant-in-Aid for Scientific Research from the Ministry of Education, Culture, Sports, Science and Technology of Japan in the Priority Area "Giant Straining Process for Advanced Materials Containing Ultra-High Density Lattice Defects" and in part by Kyushu University Interdisciplinary Programs in Education and Projects in Research Development (P\&P).

\section{REFERENCES}

1) R. Z. Valiev, R. K. Islamgaliev and I. V. Alexandrov: Prog. Mater. Sci. 45 (2000) 103-189.

2) R. Z. Valiev, I. V. Alexandrov, Y. T. Zhu and T. C. Lowe: J. Mater. Res. 17 (2002) 5-8.

3) A. P. Zhilyaev and T. G. Langdon: Prog. Mater. Sci. 53 (2008) 893979.

4) M. V. Degtyarev, T. I. Chashchukhina and L. M. Voronova: Fiz. Met. Metalloved. 77 (1994) 141-146.

5) R. K. Islamgaliev, N. F. Yunusova, I. N. Sabirov, A. V. Sergueeva and R. Z. Valiev: Mater. Sci. Eng. A 319-321 (2001) 877-881.

6) I. V. Alexandrov, Y. T. Zhu, T. C. Lowe, R. K. Islamgaliev and R. Z. Valiev: Nanostruct. Mater. 10 (1998) 45-54.

7) V. V. Stolyarov, Y. T. Zhu, T. C. Lowe, R. K. Islamgaliev and R. Z. Valiev: Mater. Sci. Eng. A 282 (2000) 78-85.

8) A. R. Yavari, W. J. Botta, C. A. D. Rodrigues, C. Cardoso and R. Z. Valiev: Scr. Mater. 46 (2002) 711-716.

9) T. Tokunaga, K. Kaneko, K. Sato and Z. Horita: Scr. Mater. 58 (2008) $735-738$.

10) T. Tokunaga, K. Kaneko and Z. Horita: Mater. Sci. Eng. A 490 (2008) 300-304.

11) A. V. Sergueeva, C. Song, R. Z. Valiev and A. K. Mukherejee: Mater. Sci. Eng. A 339 (2003) 159-165.

12) C. Rentenberger, T. Waitz and H. P. Karnthaler: Mater. Sci. Eng. A 462 (2007) 283-288.

13) J. Cizek, I. Prochazka, B. Smola, I. Stulíkova, R. Kuzel, Z. Matej, V. 
Cherkaska, R. K. Islamgaliev and O. Kulyasova: Mater. Sci. Eng. A 462 (2007) 121-126.

14) Y. Harai, M. Kai, K. Kaneko, Z. Horita and T. G. Langdon: Mater. Trans. 49 (2008) 76-83.

15) A. Vorhauer and R. Pippan: Scr. Mater. 51 (2004) 921-925.

16) F. Wetscher, A. Vorhauer, R. Stock and R. Pippan: Mater. Sci. Eng. A 387-389 (2004) 809-816.

17) S. Erbel: Met. Technol. 6 (1979) 482-486.

18) I. Saunders and J. Nutting: Metal. Sci. 18 (1984) 571-575.

19) Y. Harai, Y. Ito and Z. Horita: Scr. Mater. 58 (2008) 469-472.

20) Y. Ito, Y. Harai, T. Fujioka, K. Edalati and Z. Horita: Mater. Sci. Forum
584-586 (2008) 191-196.

21) K. Edalati, T. Fujioka and Z. Horita: Mat. Sci. Eng. A 498 (2008) 168173.

22) T. Inoue, Z. Horita, H. Somekawa and K. Ogawa: Acta Mater. (2008) in press.

23) C. Xu, Z. Horita and T. G. Langdon: Acta Mater. 55 (2007) 203-212.

24) K. Edalati, T. Fujioka and Z. Horita: Proc. 156th meeting of ISIJ and JIM: Joint Session on Current Advances in Materials and Processes, Kumamoto, Japan, 21(2) (2008) p. 516.

25) Y. Todaka, M. Umemoto, A. Yamazaki, J. Sasaki and K. Tsuchiya: Mater. Trans. 49 (2008) 7-14. 